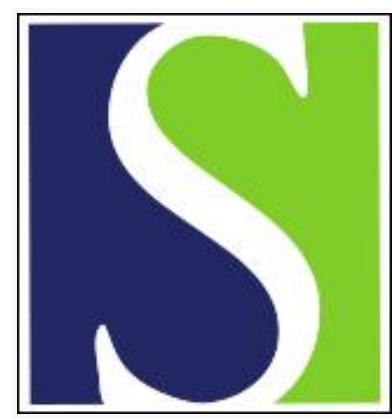

Scand J Work Environ Health 2004;30(6):450-458

https://doi.org/10.5271/sjweh.834

Issue date: Dec 2004

Development and evaluation of parental occupational exposure questionnaires for a childhood leukemia study

by Reinier K, Hammond SK, Buffler PA, Gunier RB, Lea CS, Quinlan P, Kirsch J

Affiliation: Oregon SUDS, Cardiology UHN-62, Oregon Health and Science University, 3181 SW Sam Jackson Park Road, Portland, OR 97239, USA. kreinier@uvm.edu

The following article refers to this text: 2006;32(6):463-472

Key terms: case-control study; childhood leukemia study; epidemiologic measurement; exposure assessment; job module; parental exposure; parental occupational exposure questionnaire

This article in PubMed: www.ncbi.nlm.nih.gov/pubmed/15633596 


\title{
Development and evaluation of parental occupational exposure questionnaires for a childhood leukemia study
}

\author{
by Kyndaron Reinier, PhD, ${ }^{1,2}$ S Katharine Hammond, PhD, ${ }^{3}$ Patricia A Buffler, PhD, ${ }^{1}$ Robert B Gunier, \\ MPH, ${ }^{4}$ C Suzanne Lea, PhD, ${ }^{5}$ Patricia Quinlan, $\mathrm{ClH},{ }^{6}$ Jan Kirsch, $M D^{1}$
}

\begin{abstract}
Reinier K, Hammond SK, Buffler PA, Gunier RB, Lea CS, Quinlan P, Kirsch J. Development and evaluation of parental occupational exposure questionnaires for a childhood leukemia study. Scand $J$ Work Environ Health 2004;30(6):450-458.
\end{abstract}

\begin{abstract}
Objectives This paper presents the results of a pilot study of job-specific modules developed for use in the study questionnaire of the Northern California Childhood Leukemia Study (i) to estimate the variability in response between people administered the same module and (ii) to estimate the number of modules required per family.

Methods For 63 participants in the pilot study, between-person variability was assessed by comparing reported job tasks among the respondents administered the same job-specific module. Within-respondent variability was assessed by examining changes in the timing and frequency of the job tasks and product use across critical time segments from 12 months before the child's birth to 3 years of age. Parental occupational histories were reviewed to estimate the expected number of job-specific modules required per family.

Results Considerable variability was identified for the tasks performed by the respondents with similar jobs and in the timing of tasks and products used across critical time windows. Parents' occupational histories indicated that detailed exposure information could be obtained for $95 \%$ of the families with a maximum of two job-specific modules added to the study interview.

Conclusions The job-specific modules captured individualized exposure information for the parents of cases and controls and thus reduced the potential for nondifferential misclassification when compared with the use of a job title approach, while avoiding an exposure checklist approach. These improvements in exposure estimation may increase the statistical power for identifying any true association between parental occupational exposures and childhood leukemia.
\end{abstract}

Key terms study, case-control; measurement, epidemiologic; exposure assessment; job module; exposure, parental.

Nearly 40 published case-control studies have investigated the potential relation between parents' workplace exposures and leukemia in their offspring (1). Some studies have implicated occupational exposure to solvents, pesticides, metals, paints, or plastics, but findings are inconsistent across studies. Imprecise occupational exposure assessment might explain some of the inconsistency.
Occupational exposure assessment in communitybased case-control studies is a significant challenge (2), and studies of childhood leukemia are no exception. Many case-control studies on childhood leukemia have imputed occupational exposures from job titles or brief job descriptions. This approach is limited by the nondifferential exposure misclassification resulting from the assumption that people with the same job title have the same exposures $(3,4)$.

1 School of Public Health, Division of Public Health Biology and Epidemiology, University of California, Berkeley, Berkeley, California, United States.

2 Department of Medical Biostatistics, University of Vermont College of Medicine, 25 Hills Building, Burlington, California, United States.

3 School of Public Health, Division of Environmental Health Sciences, University of California, Berkeley, Berkeley, California, United States.

4 Environmental Health Investigations Branch, California Department of Health Services, Oakland, California, United States. 5 Research Triangle Institute, Research Triangle Park, North Carolina, United States.

6 Department of Occupational Medicine, University of California, San Francisco, San Francisco, California, United States.

Reprint requests to: Dr Kyndaron Reinier, Oregon SUDS, Cardiology UHN-62, Oregon Health and Science University, 3181 SW Sam Jackson Park Road, Portland, OR 97239, USA. [E-mail: kreinier@uvm.edu] 
Another common approach in childhood leukemia studies involves asking respondents to indicate, from a list of chemicals, the agents to which they have been exposed at work. Although this "exposure checklist" approach allows for individual exposure variability, it is subject to recall bias if case and control parents remember or report exposures differently and to nondifferential misclassification if the respondents are unaware of the names of the substances they work with or are unfamiliar with chemicals in industrial processes (4, 5 ). Evidence of recall bias was found in an examination of the data from three childhood leukemia studies that used an exposure checklist approach, the fathers of case children overreporting exposures during the prenatal period (6).

There have been some recent attempts to increase the validity of exposure assessment in community-based studies of adult cancers. Siemiatycki \& Gerin $(5,7)$ developed semi-structured interviews that allow more probing about occupational tasks; occupational hygienists and chemists played a leading role in developing the interview content and interpreting the questionnaire responses. A modification of these semi-structured interviews was developed for a National Cancer Institute (NCI) study of adult brain tumors to reduce costs, decrease interviewer training needs, and facilitate data collection in a computer-assisted interview format (8, 9). These "job-specific modules" elicited information about direct and indirect exposures on the basis of work tasks and the work environment.

The Northern California Childhood Leukemia Study adapted the NCI approach of using job-specific modules $(8,9)$ to improve the assessment of parental occupational exposures. The NCI modules needed to be modified for the study so that the specific timing of parental exposures could be captured relative to the child's conception and development and the differences in exposures of interest could be accomodated, along with temporal and geographic differences in occupational patterns.

This report presents findings from a pilot study of the use of job-specific modules in the Northern California Childhood Leukemia Study. The primary goal was to evaluate the feasibility of conducting interviewer-administered job-specific modules as a complement to a 4-year job history and to identify the variability in response to task-specific activities for respondents with similar job types.

\section{Study population and methods}

\section{Study population}

The Northern California Childhood Leukemia Study, an ongoing population-based case-control study, identifies incident childhood leukemia cases via rapid case ascertainment from all major pediatric hospitals in the study region. The study methods have been previously published (10). Persons for this pilot study were selected from cases and controls from phase I of the study (19951999), which included 17 northern California counties and 4 participating pediatric treatment centers serving the population of these counties. Eligible cases were under 15 years of age, had a parent or guardian who spoke English or Spanish, had no previous cancer diagnosis or treatment, and were residents of the study area at the time of diagnosis. For each case child, a control child from the California birth register, representing the underlying source population for over $90 \%$ of the cases, was individually matched for exact date of birth, gender, maternal race, child's Hispanic status, and maternal county of residence at birth. Control eligibility was the same as for the cases.

\section{Occupational history data collection}

Prior to the in-home interview, an occupational history was obtained from a self-administered questionnaire for all jobs held by the child's mother and father during the 4-year period beginning 1 year before the child's birth and ending on the child's third birthday. This period encompasses the preconceptional, in utero, and early postnatal periods, time segments hypothesized a priori to be potentially relevant for the development of childhood leukemia (11). For each job, the respondents provided the job title, a description of job activities and duties, the dates the job was held, whether it was fulltime or part-time, the name and location of the company, and what the company did or made.

\section{Development of job-specific occupational questionnaires}

Job-specific modules were developed during phase I of the Northern California Childhood Leukemia Study to collect detailed occupational exposure information from parents whose occupational history included jobs with potential exposure to chemicals and agents identified a priori as possible leukemogens or carcinogens. The jobspecific modules were designed by a team including industrial hygienists, epidemiologists, an environmental health specialist, and a physician trained in occupational medicine, with input from collaborating toxicologists. Modules were developed for jobs prevalent in the study population with potential exposures of interest; for jobs not found in this population, such as coal miner or steel mill worker, no modules were developed. The modules included questions about tasks likely to involve exposure to relevant agents as determined by experienced industrial hygienists, reference texts $(12,13)$, published 
literature, material safety data sheets, interviews with volunteers who held jobs of interest, and on-line toxicologic databases such as the Hazardous Substances Data Bank of the National Library of Medicine's TOXNET program (http://toxnet.nlm.nih.gov/) (14). Table 1 shows the 19 job modules developed for the study and the primary exposures of interest.
Each module begins with general questions about the workplace environment, followed by a series of questions about job tasks that elicit standardized information. If a respondent performed a task, follow-up questions ask about the products, materials, equipment, or procedures used in that task. Figure 1 illustrates the format of a typical task question. Many task questions

Table 1. Job-specific module questionnaires developed for occupational exposure assessment in the Northern California Childhood Leukemia Study and selected potential exposure agents of interest assessed in each job-specific module (broad categories only).

\begin{tabular}{|c|c|c|c|c|c|c|c|c|c|}
\hline Module title & Job types included in each module & $\begin{array}{l}\text { Number } \\
\text { in pilot } \\
\text { study }\end{array}$ & $\begin{array}{l}\text { Organ- } \\
\text { ic sol- } \\
\text { vents }^{a}\end{array}$ & $\begin{array}{l}\text { Other or- } \\
\text { ganic com- } \\
\text { pounds }^{b}\end{array}$ & $\begin{array}{l}\text { Combus- } \\
\text { tion ex- } \\
\text { haust }^{c}\end{array}$ & Metals ${ }^{d}$ & $\begin{array}{l}\text { Ionizing } \\
\text { radia- } \\
\text { tion }^{e}\end{array}$ & $\begin{array}{l}\text { Pesti- } \\
\text { cides }^{f}\end{array}$ & Other \\
\hline Airplane mechanic ${ }^{g}$ & Airplane mechanic & - & $x$ & & & $x$ & $x$ & & \\
\hline Artist & Artist or art teacher & 4 & $x$ & & & $x$ & & & $x$ \\
\hline Cleaner & Cleaner or janitor & 3 & $x$ & & & & & $x$ & \\
\hline Construction worker & Construction worker or carpenter & 6 & $x$ & $x$ & $x$ & $x$ & & & $x$ \\
\hline Dentist & Dentist or dental worker & 4 & $x$ & & & & $x$ & & $x$ \\
\hline Electrician & Electrician, lineman or cable puller & 4 & $x$ & $x$ & $x$ & $x$ & & & $x$ \\
\hline Engineer & Engineer or environmental scientist & 3 & $x$ & & & & $x$ & & $x$ \\
\hline Farmer & Farm or ranch worker & 5 & $x$ & & $x$ & $x$ & & $x$ & \\
\hline Gardener & $\begin{array}{l}\text { Gardener, groundskeeper, landscaper } \\
\text { or nursery worker }\end{array}$ & 6 & $x$ & & $x$ & $x$ & & $\mathrm{x}$ & \\
\hline Laboratory worker & Laboratory worker or lab science teacher & 4 & $x$ & & & & $x$ & & $x$ \\
\hline Manufacturing worker ${ }^{g}$ & $\begin{array}{l}\text { Manufacturing, assembly, industrial } \\
\text { operations or product repair }\end{array}$ & - & $x$ & & & $x$ & & & $\mathrm{x}$ \\
\hline Mechanic & Auto, truck, or bus mechanic & 6 & $x$ & & $x$ & $x$ & & & $x$ \\
\hline Medical worker & Physician, nurse or medical technician & 5 & $x$ & & & & $x$ & $\mathrm{x}$ & $x$ \\
\hline Packer ${ }^{g}$ & Agricultural packer & - & & & & & $x$ & $x$ & \\
\hline Painter & Painter or wallpaperer & 2 & $x$ & & & & & & \\
\hline Pesticide worker & Pesticide worker & 1 & & & & & & $x$ & \\
\hline Photographer & $\begin{array}{l}\text { Photographer or framer or photography } \\
\text { teacher }\end{array}$ & 2 & $\mathrm{x}$ & & & & & & \\
\hline Teacher & Teacher of preschool to grade 5 & 9 & $x$ & & & & & & $x$ \\
\hline Welder & Welder or joiner & 3 & $x$ & & $x$ & $x$ & & & $x$ \\
\hline
\end{tabular}

Total

67

a Organic solvents included aromatic solvents, chlorinated solvents, glycol ethers, and other hydrocarbon mixtures.

${ }^{b}$ Other organic compounds included coal tars, asphalt, and creosote.

c Combustion exhaust included gasoline and diesel exhaust and emissions and polyaromatic hydrocarbons.

d Metals included welding fumes and metal dusts.

Ionizing radiation included exposures from imaging radiation equipment, diagnostic equipment, and work with radioactive materials.

† Pesticides included those used in agriculture and landscaping, as well as other uses, including structural purposes, medical purposes, and disinfection.

${ }^{9}$ Modules not included in the pilot study.

7a. At your job during this time [PERIODS MARKED ON CALENDAR], did you paint or use other coatings? (Including lacquers, varnishes, stains, and others)

\begin{tabular}{|c|c|c|c|c|c|}
\hline \multirow[t]{9}{*}{$\begin{array}{l}1=\text { Yes } \rightarrow \\
2=\text { No } \rightarrow \\
\text { GO TO } \\
\text { Q11 } \\
9=\text { DK } \rightarrow \\
\text { GO TO } \\
\text { Q11 }\end{array}$} & (i) Did you use... & (ii) Was this during... & $\begin{array}{l}\text { (iii) How many } \\
\text { days per week } \\
\text { during this } \\
\text { period? } \\
1=<1 \\
2=1-2 \\
3=3-5 \\
9=\text { DK }\end{array}$ & $\begin{array}{l}\text { (iv) On those } \\
\text { days, how } \\
\text { many hours } \\
\text { per day, } \\
\text { usually? } \\
1=<1 \\
2=1-4 \\
3=>4 \\
9=\text { DK }\end{array}$ & 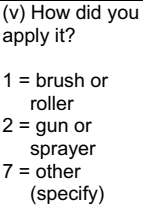 \\
\hline & \multirow{3}{*}{$\begin{array}{l}\text { a. water-based paints, } \\
\text { such as latex? }\end{array}$} & $\begin{array}{l}\square 3 \text { months before } \\
\text { pregnancy }\end{array}$ & & & \\
\hline & & $\square 1^{\text {st }}$ trimester & & & \\
\hline & & $\square 2^{\text {nd }}$ trimester & & & \\
\hline & \multirow{3}{*}{$\begin{array}{l}1=\text { Yes } \rightarrow \text { What } \\
\text { type or brand? }\end{array}$} & 口 $3^{\text {rd }}$ trimester & & & \\
\hline & & while breastfeeding & & & \\
\hline & & birth to age 1 & & & \\
\hline & \multirow{2}{*}{$\begin{array}{l}2=\mathrm{No} \\
9=\mathrm{DK}\end{array}$} & age 1 to 2 & & & \\
\hline & & age 2 to 3 & & & \\
\hline
\end{tabular}

Figure 1. Example of a typical task question format in a job-specific module. 
appear in more than one module. For example, the question, "At your job during this time, did you paint or use other coatings?" appears in the following modules: airplane mechanic, artist, construction worker, farmer, gardener, manufacturing worker, mechanic, painter, photographer, and teacher. When possible, common product names rather than specific chemical names were used. Questions about the task method (eg, spray versus brush painting) and the personal protective equipment used in the task (eg, paper mask or respirator) were included if applicable.

For each product, material, piece of equipment, or procedure reported by a respondent, the timing of use was queried to establish when use occurred during critical periods in the child's development (3 months before pregnancy, each trimester, during breastfeeding if applicable, and the first 3 years of life) (figure 1). Some tasks required no follow-up questions about products or procedures; for these, timing was queried for the task itself. A calendar card marked with events in the child's development was used during the interview to assist the recall of timing. Frequency of use was also queried for each of the periods reported, usually in days per week and hours per day (figure 1).

The design of the job-specific modules facilitates analysis at many levels, including job task (eg, painting), commercial product (eg, solvent-based paint), broad chemical group (eg, liquid hydrocarbon solvent), chemical subgroup (eg, aromatic solvent), and specific chemical (eg, toluene), for specific time periods relative to the child's development. Information about frequency of use allows a relative exposure level to be assigned within and across respondents by time period.

The job-specific modules were designed to be given in face-to-face interviews with the biological parent jobholder; ample evidence suggests that proxy respondents are not able to provide reliable, detailed occupational information $(15,16)$. Brevity was deemed essential to avoid respondent fatigue. The overall in-home study interview requires 60-90 minutes; thus, the modules were designed to be administered in 20 minutes or less.

For each module, an exposure coding scheme has been developed for each of the tasks, as well as for each product, material, piece of equipment, and procedure used in each task. A respondent's exposure assignments are based on this predefined scheme and depend on the person's reported tasks and the products or procedures used. A detailed discussion of the exposure assessment methods is beyond the scope of this paper and will be presented in a subsequent report. In general, in order to minimize false positives, exposures have been assigned to tasks, products, materials, equipment, and procedures only if deemed likely to occur by an experienced industrial hygienist. This approach is based on the principle that, in a case-control study with low exposure prevalence, the odds ratio will be strongly biased toward the null by misclassification of even a few unexposed persons into the exposed category (false positives), while the misclassification of exposed persons into the unexposed category (false negatives) has a less pronounced effect on bias (17).

\section{Pilot study with the job-specific modules}

Data collection. A pilot study of the job-specific modules was conducted from September 1999 to February 2000 to test the feasibility and performance of the modules in the field. The respondents were people who had completed the self-administered questionnaire and inhome interview between 1996 and 1999 and whose occupational history included a job of interest. The researchers reviewed the occupational histories and assigned job-specific modules based on the job title, industry, and brief job description. Trained interviewers performed in-person interviews with the participants in the pilot study. An attempt was made to obtain three interviews for each of the 16 job-specific modules developed at the time; a total of 67 module interviews were completed.

Data analysis. Between-person exposure variability, as measured by the variability in reported tasks among respondents administered the same job-specific module, was used as a measure of job module advantage. Substantial variability across participants with similar jobs would indicate the usefulness of the modules in characterizing exposure at an individual level.

Within-person variability in the timing of exposure was calculated as the proportion of tasks, products, materials, equipment, or procedures reported by that person for which the timing of use differed from the overall time the job was held. For example, a carpenter who held her job from 3 months before pregnancy through the child's first year of life, but painted with solventbased paints only during the first two trimesters of pregnancy, had variability in timing of exposure for that product. A higher proportion of tasks and products with variability in timing would indicate that obtaining exposure information by time period may be informative. Variability could not be calculated for the small number of tasks and products used over only one period.

Similarly, each person's reported frequency of use of products, materials, equipment, or procedures was examined to determine whether frequency changed over the time segments. For example, if a female carpenter used solvent-based paints for 3 days a week during her first trimester, but $<1$ day a week during her second trimester, this product had variability in frequency. The proportion of total reported products with variability in 
frequency would indicate the benefit of obtaining exposure information at this level of detail. Variability was calculated only for tasks performed or products used for more than one period.

Finally, to evaluate the feasibility of introducing the job-specific modules into the protocol of the ongoing Northern California Childhood Leukemia Study, occupational history data were reviewed for parents of all the study participants interviewed before February 2000 to predict the number of modules required per family in future interviews (including both parents of a twoparent family).

\section{Results}

The pilot study resulted in 67 completed module interviews with 63 parents of 56 children from phase I of the Northern California Childhood Leukemia Study (36 case modules; 31 control modules). Thirty-three modules were completed by mothers and 34 by fathers.

The average time used to complete one module was 26 (SD 17) minutes; the time required did not differ for the cases and controls (24.0 versus 28.8 minutes, $\mathrm{P}=0.30$ ). The fathers required more time, on the average, than the mothers (32.5 versus 18.8 minutes, $\mathrm{P}=0.002$ ). Much of the variability in the administration time within each module was explained by the number of tasks the respondent reported.

\section{Variability in number of reported tasks}

Table 2 presents the average percentage of tasks performed per module, which ranged from $14 \%$ (teacher) to $88 \%$ (painter) and therefore indicated that the likelihood of performing tasks with potential exposures of interest varied across job types. The range of tasks reported by the respondents to each module showed substantial variability for most of the modules, particularly the artist, construction worker, electrician, and mechanic modules. For example, one respondent to the artist module did no task of interest, while another did $60 \%$ of the tasks. There was also considerable variability in the number of products used while the tasks were being done.

The respondents were able to answer nearly all of the task-based questions affirmatively or negatively. In the 67 module interviews, with over 700 task questions asked, there were only two "don't know" responses to whether a task was performed.

\section{Variability in timing}

Within-person variability in worktasks and product use across the time segments is presented by job-specific module in table 2 . The modules with little or no variability in timing included the artist, dentist, painter, and photographer modules. For example, the respondents to the dentist module reported timing variability for an average of only $4 \%$ of the tasks, products, materials, equipment, or procedures, a finding suggesting regular

Table 2. Between-subject variability in reported tasks and products and within-subject variability in the timing and frequency of reported tasks and products.

\begin{tabular}{|c|c|c|c|c|c|c|c|c|c|}
\hline \multirow[t]{2}{*}{ Module a } & \multirow[t]{2}{*}{$\begin{array}{l}\text { Tasks } \\
\text { queried in } \\
\text { module } \\
\text { (N) }\end{array}$} & \multicolumn{2}{|c|}{$\begin{array}{l}\text { Average percentage } \\
\text { of tasks performed } \\
\text { by pilot study } \\
\text { respondents }\end{array}$} & \multicolumn{2}{|c|}{$\begin{array}{l}\text { Products reported } \\
\text { used while per- } \\
\text { forming tasks } \\
\text { (N) }\end{array}$} & \multicolumn{2}{|c|}{$\begin{array}{l}\text { Variability in timing } \\
\text { (percentage of pro- } \\
\text { ducts reported with } \\
\text { variability in } \\
\text { timing of use) }{ }^{b}\end{array}$} & \multicolumn{2}{|c|}{$\begin{array}{c}\text { Variability in fre- } \\
\text { quency (percentage } \\
\text { of products reported } \\
\text { with variability in } \\
\text { frequency of use) }{ }^{b}\end{array}$} \\
\hline & & Mean & Range & Mean & Range & Mean & Range & Mean & Range \\
\hline Artist & 15 & 20 & $0-60$ & 7.0 & $3-25$ & 0 & .. & 0 & .. \\
\hline Cleaner & 9 & 44 & $33-56$ & 6.7 & $4-10$ & 18 & $0-30$ & 0 & .. \\
\hline Construction worker & 20 & 50 & $20-75$ & 18.0 & $3-35$ & 20 & $0-73$ & 6 & $0-27$ \\
\hline Dentist & 9 & 64 & $56-78$ & 6.5 & $5-9$ & 4 & $0-17$ & 0 & .. \\
\hline Electrician & 7 & 36 & $0-71$ & 3.3 & $0-8$ & 10 & $0-20$ & 0 & .. \\
\hline Engineer & 6 & 50 & $33-67$ & 15.0 & $6-20$ & 60 & $0-100$ & 0 & .. \\
\hline Laboratory worker & 8 & 27 & $13-38$ & 9.8 & $5-17$ & 24 & $0-40$ & 0 & .. \\
\hline Mechanic & 15 & 62 & $40-87$ & 14.5 & $6-24$ & 41 & 8-55 & 14 & $0-46$ \\
\hline Medical worker & 14 & 26 & $7-43$ & 3.6 & $1-8$ & 58 & $20-100$ & 0 & .. \\
\hline Painter & 8 & 88 & $75-100$ & 17.0 & $11-23$ & 4 & 0-9 & 0 & .. \\
\hline Photographer & 11 & 18 & 0-36 & 4.5 & 0-9 & 0 & .. & $29^{c}$ & .. \\
\hline Teacher & 9 & 14 & $0-33$ & 2.2 & $1-4$ & 67 & $0-100$ & 25 & $0-50$ \\
\hline Welder & 10 & 60 & $40-80$ & 8.3 & $4-14$ & 15 & $0-45$ & 0 & .. \\
\hline
\end{tabular}

a Farmer, gardener, and pesticide worker modules not included in the table because their formats differed from other modules, with tasks, timing, and frequency ascertained by crop and season.

b See text for the definition of variability in timing and frequency.

${ }^{c}$ Of two respondents, one reported performing no tasks included in the job-specific module. 
task performance and product use. Others, such as the engineer, mechanic, medical worker, and teacher modules had a high proportion of tasks or products with variability in timing, a finding indicating that these respondents performed tasks or used products in a more sporadic manner. Variability in timing can be used to examine the importance of when exposures occur during a child's development.

\section{Variability in frequency of use of products and materials}

Little within-person variability was found for the reported frequency of tasks, products, materials, equipment, or procedures (table 2). For several modules, the respondents reported no variability; tasks were performed or products were used with the same frequency over all the time segments.

\section{Illustration of task-based information}

Tables 3 and 4 (on page 456) illustrate, using two jobspecific modules, how the detailed task-based information resulted in unique exposure profiles. Among the six respondents to the construction worker module, for example, four painted, one stripped paints, five worked with wood, and three did roofing work (table 3 ). The respondents reported using different types of products, materials, equipment, or procedures while performing tasks and therefore provided another level of exposure detail. Interestingly, the job tasks of some of the respondents with different self-reported job titles (eg, carpenter versus contractor) appeared to be no less similar than the tasks of the respondents with the same job title. Of five respondents to the medical worker module, two indicated a job title of "medical assistant", and three were nurses (one "staff nurse" and two "registered nurses") (table 4). The tasks reported by the nurses were more similar than those reported by the medical assistants. However, there remained considerable task variability across the three nurses, only one nurse reporting working in a room with anesthetic gases, one performing radiation therapy implants, and one operating imaging radiation equipment.

\section{Feasibility}

On the basis of the self-reported occupational histories of the parents of 331 persons enrolled in the Northern California Childhood Leukemia Study as of February 2000 , we determined that $48 \%$ of the fathers and $38 \%$ of the mothers would require at least one module for jobs held during the 4-year period of interest. The most commonly required modules were construction worker (required by approximately $7 \%$ of the parents), manu- facturing worker (5\%), teacher (5\%), electrician $(5 \%)$, and cleaner (4\%). When both parents' work histories were combined, no job-specific module would be required for $40 \%$ of the families, while $38 \%$ would require one module, $17 \%$ would require two modules, and the remaining $5 \%$ would require three or four modules; this result indicates that detailed occupational exposure information can be obtained for $95 \%$ of families with a maximum of two modules.

\section{Evidence of differential reporting in the open-ended question}

The final question on the modules was open-ended: "Is there any other information you would like to mention about your job duties during the time beginning one year before $\{$ the index child's $\}$ birth up to his/her third birthday?" Thirty-one of the 67 respondents (46\%) provided responses, including clarification of answers already given in the module, additional chemical exposures, and information about work practices or environment. While similar proportions of case and control parents answered the open-ended question, 9 of the 12 respondents who provided a specific chemical name were case parents. Of the six respondents who provided the name of a chemical of a priori interest to the study, five were case parents. Two case parents also reported exposure to electromagnetic frequency radiation, a well-publicized exposure that was not assessed in the modules. These results indicate the potential for differential reporting of exposure in open-ended questions.

\section{Discussion}

The purpose of the pilot study was to test the feasibility and usefulness of job-specific modules developed to obtain detailed information on workplace exposure from parents in a childhood leukemia study. The job-specific modules identified substantial interindividual exposure variability due to differences in the tasks performed and products used by parents administered the same module and identified moderate intraindividual variability in the timing of the use of products (and thus the timing of exposures) across critical time segments relative to the child's conception and growth. This detailed information allows an evaluation of exposures at specific times during a child's development.

The job-specific modules were not as effective in eliciting within-person variability in exposure frequency across time segments, either because there was little actual variability in the frequency with which the respondents performed the tasks or used the products or because the respondents were not able to remember 
Table 3. Specific tasks and number of products reported for six respondents to the construction worker job-specific module. ( $X=$ task was reported; number in parentheses = number of products, materials, pieces of equipment, or procedures used while performing that task; - = no follow-up question about products was asked for this task)

\begin{tabular}{|c|c|c|c|c|c|c|}
\hline \multirow[t]{2}{*}{ Construction worker module } & \multicolumn{6}{|c|}{ Self-reported job title a,b,c,d } \\
\hline & $\begin{array}{l}\text { Subject A } \\
\text { (carpenter) }\end{array}$ & $\begin{array}{l}\text { Subject B } \\
\text { (carpenter) }\end{array}$ & $\begin{array}{c}\text { Subject C } \\
\text { (building } \\
\text { remodeling) }\end{array}$ & $\begin{array}{l}\text { Subject D } \\
\text { (construction } \\
\text { carpentry } \\
\text { worker) }\end{array}$ & $\begin{array}{l}\text { Subject E } \\
\text { (contractor } \\
\text { or grading } \\
\text { contractor) }\end{array}$ & $\begin{array}{c}\text { Subject F } \\
\text { (concrete } \\
\text { contractor) }\end{array}$ \\
\hline Paint or apply other coatings & $X(1)$ & $X(4)$ & & $X(3)$ & $X(4)$ & \\
\hline \multicolumn{7}{|l|}{ Thin paints with anything other than water } \\
\hline Clean brushes with anything other than soap and water & & $X(4)$ & & $X(4)$ & $X(6)$ & \\
\hline Clean up dried paint & & $X(1)$ & & $X(1)$ & $X(2)$ & \\
\hline Do paint stripping & & $X(2)$ & & & & \\
\hline $\begin{array}{l}\text { Wash hands with anything other than soap and water } \\
\text { Hang or strip wallpaper }\end{array}$ & $X(2)$ & $X(5)$ & $X(4)$ & $X(3)$ & $X(6)$ & $X(1)$ \\
\hline Work with wood (eg, sawing, planing, sanding) & $X(3)$ & $X(3)$ & $X(3)$ & $X(2)$ & $X(3)$ & \\
\hline Work with cement, concrete, or mortar & $X(1)$ & $X(1)$ & $X(1)$ & $X(1)$ & $X(1)$ & $X(1)$ \\
\hline Do caulking & & $X(1)$ & $X(1)$ & $X(1)$ & $X(1)$ & \\
\hline Install or remove insulation & $X(1)$ & $X(2)$ & $X(3)$ & & $X(3)$ & \\
\hline Use glues or adhesives & $X(1)$ & $X(1)$ & $X(2)$ & & $X(4)$ & \\
\hline \multicolumn{7}{|l|}{ Do welding } \\
\hline Do roofing or shingling & & $X(1)$ & $X(2)$ & & $X(1)$ & \\
\hline \multicolumn{7}{|l|}{ Work with hot asphalt or coal tar } \\
\hline Do demolition work & $X(-)$ & $X(-)$ & $X(-)$ & $X(-)$ & $X(-)$ & $X(-)$ \\
\hline Handle asbestos or work near others working with asbestos & & $X(-)$ & $X(-)$ & & $X(-)$ & \\
\hline Do electrical work & & $X(1)$ & & & & \\
\hline Do plumbing & & & & $X(0)$ & $X(1)$ & \\
\hline
\end{tabular}

${ }^{a}$ Number of reported tasks (of 20 total): 8 for subject $A, 15$ for subject $B, 9$ for subject $C, 10$ for subject $D, 14$ for subject $E$, and 4 for subject $F$.

b Number of products (product, material, equipment, or procedure asked as follow-up to main task question) used while the reported tasks were done:

10 for subject $A, 28$ for subject $B, 16$ for subject $C, 16$ for subject $D, 35$ for subject $E$, and 3 for subject $F$.

c Proportion of products for which timing of use varied across at least one time segment (when no follow-up question was asked, timing was asked for the task itself): $73 \%$ for subject $A, 0 \%$ for subject $B, 6 \%$ for subject $C, 24 \%$ for subject $D, 18 \%$ for subject $E$, and $0 \%$ for subject $F$.

d Proportion of products for which frequency of use varied across at least one time segment (when no follow-up question was asked, frequency was asked for the task itself): $27 \%$ for subject $A, 3 \%$ for subject B, $0 \%$ for subject C, $0 \%$ for subject $D, 8 \%$ for subject $E$, and $0 \%$ for subject $F$.

Table 4. Specific tasks and number of products reported for five respondents to the medical worker, job-specific module. (X = task was reported; number in parentheses $=$ number of products, materials, pieces of equipment, or procedures used while the task was performed; - = no follow-up question about products was asked for this task)

\begin{tabular}{|c|c|c|c|c|c|}
\hline \multirow[t]{2}{*}{ Medical worker module } & \multicolumn{5}{|c|}{ Self-reported job title a, b, c, d } \\
\hline & $\begin{array}{l}\text { Subject A } \\
\text { (registered } \\
\text { nurse) }\end{array}$ & $\begin{array}{l}\text { Subject B } \\
\text { (registered } \\
\text { nurse) }\end{array}$ & $\begin{array}{l}\text { Subject C } \\
\text { (staff } \\
\text { nurse) }\end{array}$ & $\begin{array}{l}\text { Subject D } \\
\text { (medical } \\
\text { assistant) }\end{array}$ & $\begin{array}{l}\text { Subject E } \\
\text { (medical } \\
\text { assistant) }\end{array}$ \\
\hline $\begin{array}{l}\text { Spend time in a room with anesthetic gases } \\
\text { Work in nuclear medicine (mix, prepare, etc) }\end{array}$ & $X(3)$ & & & & \\
\hline Make radiation therapy implants & & $X(-)$ & & & \\
\hline $\begin{array}{l}\text { Operate/work near imaging radiation equipment } \\
\text { Develop X-ray or other films } \\
\text { Mix antineoplastic drugs }\end{array}$ & $X(1)$ & & & & \\
\hline $\begin{array}{l}\text { Do other work with antineoplastic drugs } \\
\text { Spend time in a room with aerosolized drugs }\end{array}$ & & $X(-)$ & $X(-)$ & & \\
\hline Use disinfectants & $X(2)$ & $X(2)$ & $x(3)$ & $X(1)$ & $X(2)$ \\
\hline Spend time in work area with sterilizers & $x(2)$ & & & & $X(1)$ \\
\hline Work while laser, electrocautery surgery done & $X(-)$ & & & & \\
\hline Spend time in room with formaldehyde & $X(-)$ & & & & $X(-)$ \\
\hline Accidentally exposed to blood products & & $X(-)$ & $X(-)$ & & \\
\hline Apply treatment for patients with lice or scabies & & $X(1)$ & & & \\
\hline
\end{tabular}

a Number of reported tasks (of 14 total): 6 for subject $A, 5$ for subject $B, 3$ for subject $C, 1$ for subject $D$, and 3 for subject $E$.

${ }^{b}$ Number of products (product, material, equipment, or procedure asked as follow-up to main task question) used while the reported tasks were done: 8 for subject $A, 3$ for subject $B, 3$ for subject $C, 1$ for subject $D$, and 3 for subject $E$.

c Proportion of products for which timing of use varied across at least one time segment (when no follow-up question was asked, timing was asked for the task itself): $20 \%$ for subject $A, 60 \%$ for subject $B, 50 \%$ for subject $C$, was $100 \%$ for subject $D$, and not applicable to subject $E$ (variability in timing of use not calculated for subject $E$ because the job was held for only one time segment).

d Proportion of products for which frequency of use varied across at least one time segment (when no follow-up question was asked, and frequency was asked for the task itself): $0 \%$ for subject A, $0 \%$ for subject B, $0 \%$ for subject $C$, not applicable to subject $D$, and not applicable to subject $E$ [variability in frequency of use not calculated for products used or tasks performed for only one time segment (subjects D and E)]. 
changes in frequency. This finding indicates that questions about frequency by time segment did not provide useable information. Therefore, after the pilot study, the job-specific modules were edited to query frequency of use for each product overall, rather than within each time segment. This streamlined approach still produces a measure of the frequency of use for a product that will allow an evaluation of exposure-response relationships.

There are some limitations to the use of job-specific modules. First, parents may have difficulty remembering occupational events in detail. However, the NCI modules $(8,9)$, on which the present modules were based, addressed this issue by incorporating principles to improve recall, including "priming" the respondents" memory by obtaining a complete work history before asking detailed questions, using language with which the respondent is familiar, and decomposing questions about frequency into easily understood categories, such as days per week (9). These same cognitive principles were applied in the modules used in the Northern California Childhood Leukemia Study, although their effectiveness has not yet been evaluated.

There was no opportunity in this study to corroborate the information gathered in the interviews that used job-specific modules. This limitation is shared by all currently used methods of occupational exposure assessment in population-based studies of childhood leukemia. Compared with an analysis of chemical exposures imputed from job titles, however, the job-specific modules provide a richer picture of a parent's likely task-specific and time-specific exposures.

As with any data collected directly from a person, there is the possibility of case reporting bias. Results from the one open-ended question on the job-specific modules indicated that, when free to volunteer exposure information, case parents were more likely to name specific exposures, indicating possible recall bias with the use of the less structured question. Therefore, the openended question will not be used to assign any occupational exposures in the Northern California Childhood Leukemia Study. The standardized, closed-ended question format of the job-specific modules, which asked about agents of a priori interest only within the context of specific worktasks, was an attempt to reduce this type of recall bias (9). Evidence suggests that structured questions may reduce reporting bias; for example, in a case-control study of neuroblastoma, case parents were more likely than control parents to volunteer occupational exposure information in an open-ended format, while structured questions elicited similar reported frequencies for broad exposure types (18).

This pilot study demonstrated that the use of time intensive, task-based job-specific modules was feasiblewith an estimated $40 \%$ of the families in the study population requiring no job-specific module, $38 \%$ requiring one job-specific module, and $17 \%$ requiring two jobspecific modules. The issue of feasibility is now being monitored with full implementation of the job-specific modules in phase II of the Northern California Childhood Leukemia Study, and preliminary data indicate that these predictions were accurate. If the job-specific modules were used in different study populations, the number and type of modules required would no doubt vary depending on the study population and geographic area.

Exposure misclassification has been a major limitation in previous studies of parental occupational exposures and childhood disease. This pilot study demonstrated the feasibility and usefulness of collecting taskspecific information on selected jobs. The potential reduction in misclassification by using the task-based jobspecific modules may increase the specificity of exposure assessment and thereby increase the statistical power of the Northern California Childhood Leukemia Study to observe any true associations between parental occupational exposures and childhood leukemia. Such an approach may also be feasible for other retrospective studies of parental occupational exposures and child outcomes.

\section{Acknowledgments}

The authors thank the numerous volunteers who generously spoke to us about their jobs and allowed us to observe them in their workplaces. This study was supported by grants from the National Institute of Environmental Health Sciences (PS42 ES04705 and RO1 ES09137).

\section{References}

1. Colt JS, Blair A. Parental occupational exposures and risk of childhood cancer. Environ Health Perspect 1998;106 Suppl 3:909-25.

2. Teschke K, Olshan AF, Daniels JL, De Roos AJ, Parks CG, Schulz M, et al. Occupational exposure assessment in casecontrol studies: opportunities for improvement. Occup Environ Med 2002;59:575-94.

3. Stewart PA, Stewart WF. Occupational case-control studies: II. Recommendations for exposure assessment. Am J Ind Med 1994;26:313-26.

4. Benke G, Sim M, Fritschi L, Aldred G, Forbes A, Kauppinen T. Comparison of occupational exposure using three different methods: hygiene panel, job exposure matrix (JEM), and self reports. Appl Occup Environ Hyg 2001;16(1):84-91.

5. Gerin M, Siemiatycki J. The occupational questionnaire in retrospective epidemiologic studies: recent approaches to community-based studies. Appl Occup Environ Hyg 1991; $6(6): 495-9$. 
6. Schuz J, Spector L, Ross JL. Bias in studies of parental selfreported occupational exposures and childhood cancer. Am J Epidemiol 2003;158(7):710-16.

7. Gerin M, Siemiatycki J, Kemper H, Begin D. Obtaining occupational exposure histories in epidemiologic case-control studies. J Occup Med 1985;27(6):420-6.

8. Stewart PA, Stewart WF, Heineman EF, Dosemeci M, Linet M, Inskip PD. A novel approach to data collection in a casecontrol study of cancer and occupational exposures. Int $\mathrm{J}$ Epidemiol 1996;25(4):744-52.

9. Stewart PA, Stewart WF, Siemiatycki J, Heineman EF, Dosemeci M. Questionnaires for collecting detailed occupational information for community-based case control studies. Am Ind Hyg Assoc J 1998;58:39-44.

10. Ma X, Buffler PA, Selvin S, Matthay KK, Wiencke JK, Wiemels JL, et al. Daycare attendance and risk of childhood acute lymphoblastic leukaemia. Br J Cancer 2002; 110(9):1419-24.

11. Anderson LM, Diwan BA, Fear NT, Roman E. Critical windows of exposure for children's health: cancer in human epidemiological studies and neoplasms in experimental animal models. Environ Health Perspect 2000;108 Suppl 3:573-94.

12. Parmeggiani L. Encyclopaedia of occupational health and safety. Geneva: International Labour Organisation, 1983.

13. Greenberg MI, Hamilton RJ, Phillips SD. Occupational, industrial, and environmental toxicology. St Louis (MO): Mosby; 1997.

14. Toxicology Data Network (TOXNET®) [database on the Internet]. Bethesda (MD): National Library of Medicine, Specialized Information Services. Available from http:// toxnet.nlm.nih.gov/

15. Boyle CA, Brann EA, the Selected Cancers Cooperative Study Group. Proxy respondents and the validity of occupational and other exposure data. Am J Epidemiol 1992;136(6):71221.

16. Semchuck KM, Love EJ. Effects of agriculture work and other proxy-derived case-control data on Parkinson's disease risk estimates. Am J Epidemiol 1995;141(8):747-54.

17. Dosemeci M, Stewart PA. Recommendations for reducing the effects of exposure misclassification on relative risk estimates. Occup Hyg 1996;3:169-76.

18. Teschke K, Smith JC, Olshan AF. Evidence of recall bias in volunteered vs. prompted responses about occupational exposures. Am J Ind Med 2000;38:385-8.

Received for publication: 31 December 2003 